\title{
The potential for using gamification in academic libraries in order to increase student engagement and achievement
}

\author{
Best Practice Article
}

\author{
Andrew Walsh * \\ University of Huddersfield
}

\begin{abstract}
This paper discusses the potential benefits of using gamification techniques to increase student engagement with library resources. It outlines the link between student use of library resources and academic achievement, and suggests that gamification has to potential to increase usage of resources, which may also increase academic achievement. Some early findings from an implementation of a gamification project, Lemontree, are also discussed in which students reported increased usage of library resources and their acceptance of gamification techniques in Higher Education.
\end{abstract}

Keywords: game based learning; gamification; play; libraries

\author{
*Contact: \\ Andrew Walsh \\ University of Huddersfield, UK \\ E-mail: a.p.walsh@hud.ac.uk
}




\section{Student use of the library and impact on achievement}

There has been long standing discussion in the professional and academic literature about the need to measure student usage of the library and its impact on their achievement. This dates back to at least the 1960s, with Lane (1966) onwards exhorting us to look at our impact on undergraduates' academic achievement.

Several studies in the 1960s (Astin, 1968; Nichols, 1964; Rock, Centra, \& Linn, 1970) found either weak or no correlations between library books per student and student grades. There was one exception, Barkey (1965) found a direct correlation between average grade and the number of books borrowed over two study periods of thirty days each. He was concerned, however, with the amount of students in his sample $37 \%$ and $38 \%$ in the two periods) that didn't withdraw any books at all.

The issues around reliable collection of the large datasets required to tests assumptions around library usage and impact has meant that often research has relied on self-reported benefits of library use. For instance, Nagata (2007) examined different types of library usage and found some increase in self-reported improvements in library users (such as technical knowledge and critical thinking), but primarily noted that the library is not just used for study purposes, so many issues cloud the possible correlations.

Recently, however, the routine collection of large datasets of student behaviour in universities and the capacity to analyse such data has meant large scale quantitative research is now considerably easier to achieve. The Library Impact Data project and other projects linked to it (Stone \& Collins, 2013; Stone \& Ramsden, 2013) have found a direct correlation between the use of library resources and academic achievement in undergraduates. The projects built on the studies that used smaller datasets from the 1960s onwards. The Library Impact Data Project results indicated that there were statistically relevant links between the number of books a student borrowed from a university library and the final grade they achieved in their degree. There were similarly strong links between the amount students used electronic resources and their final degree classification. There are weaker, but still statistical relevant, correlations between usage of library resources and the retention of students, with students who used more resources, less likely to leave university before their course ends.

This resurgence in research prompts the consideration of whether there is causal link as well as a correlative one, which is difficult to prove. If there is a casual link, then it would be worth introducing interventions that affect library usage, particularly amongst groups that are low users of the library, in order to improve academic achievement and retention.

The wider literature on 'student engagement' in education, which may be defined as "the extent to which students take part in educationally effective activities (Kuh, Kinzie, Buckley, Bridges, \& Hayek, 2006, p. 7) provides a wider context to engagement with library resources. In the literature on student engagement, there are similar strong correlative links between engagement in a range of practices and desirable student outcomes (such as grades and retention), but like the library usage findings, it is difficult to prove casual links (Axelson \& Flick, 2011). However, in a study that compares students across institutions that report higher levels of student engagement, it seems that increases in student engagement does increase critical thinking and grade point averages (Carini, Kuh, \& Klein, 2006). These results suggest that as wider engagement in positive behaviours is likely to improve student outcomes, so the particular case of increasing library usage may also improve outcomes shown previously to be correlated. The difficulty in allowing for the wide range of potential factors means that it is hard to be sure that increasing library usage will improve student outcomes, but as one factor among many, is worth exploring. 


\section{Play, Gamification and the Library}

There may be many ways of trying to increase usage of library resources, but this paper explores one particular type of intervention, using gamification techniques, and shows some preliminary results of a gamification project.

A university library can be an intimidating and scary place for many new students and staff, with library anxiety (Carlile, 2007; Mellon, 1986) being a well-recognised and long standing issue for academic libraries worldwide. Library anxiety is not the only reason for low use of academic libraries, of course, but bringing elements of play and games into the library may help to engage users, especially current low users of library services, with library resources and to help them see the library as a more approachable environment. This is especially as "personal interaction appears to be the central component of reduction strategies and suggestions aimed at alleviating students' fears of the academic library" (Carlile, 2007, p. 138) and play and games are inherently social activities, introducing high levels of personal interaction.

Bringing play into the library space is particularly appealing, as "play" can help us feel we are in a safe environment to experiment and to learn new things that we may otherwise be reluctant to do. Play is tricky to define, but a classic definition from Huizinga (1949) is as follows:

Summing up the formal characteristic of play, we might call it a free activity standing quite consciously outside 'ordinary' life as being 'not serious' but at the same time absorbing the player intensely and utterly. It is an activity connected with no material interest, and no profit can be gained by it. It proceeds within its own proper boundaries of time and space according to fixed rules and in an orderly manner. It promotes the formation of social groupings that tend to surround themselves with secrecy and to stress the difference from the common world by disguise or other means (p. 13).

Brown splits it down into some key features in his definition of play, stating that play is "Apparently Purposeless (done for its own sake); Voluntary; has Inherent Attraction; Freedom from time; Diminished consciousness of self; Improvisational potential; and Continuation desire" (Brown \& Vaughan, 2010 p. 17).

These definitions make bringing more play into the library, seem an attractive proposition. If we could bring such completely voluntary, seemingly purposeless activity into the library, with its "inherent attraction" and "continuation desire," it may help to reduce library anxiety and increase library activity for our some library users.

Furthermore, there is evidence that play within a learning context could help prepare our students for academic and vocational work. In conversation with a researcher who studies animals at play, Scott Brown asked why animals (in this case, bears) play. The response (Brown \&Vaughan, 2010) was "In a world continuously presenting unique challenges and ambiguity, play prepares bears for an evolving planet" (p. 29). Brown also believes that with enough play, the brain works better. "In an unpredictable, changing world, what we learn from playing can be transformed into other novel contexts." (p. 43). Students find themselves in a rapidly changing and challenging environment, especially when they first start to learn how to use a large academic library, so play can help prepare them for the vicissitudes of study and future employment.

Within libraries in particular, it is suggested that through play, an organisation like a library can engage "the whole person", building a culture of commitment, trust and creativity (Kurt, Kurt, \& Medaille, 2010), though they are primarily discussing staff rather than user relationships. Sukovic, Litting and England (2011), however, in their call for more "playful engagement" see play as a powerful tool to apply to staff and users. 
It is difficult to find ways to bring pure, independent, free play into the library, but constraining and managing it, that is turning play into a game, or using elements of games and play for a gamification project may be easier. As such there are many examples of using games for particular purpose, such as improving information skills (Foster \& Gadd, 2013; Gallegos, Allgood, \& Grondin, 2007; Markey et al., 2008; McDevitt, 2011; Smale, 2011; Taylor, Davis, Gonzalez, Dinsmore, \& Frey, 2008), or for orientation exercises (Fitz-Walter, Tjondronegoro, Koh, \& Zrobok, 2012; Rosenstein, 2013; Smith \& Baker, 2011). There are, however, limited examples in the academic literature of using play, games or gamification purely for increasing engagement with libraries and their resources, despite the recognition of its potential for this purpose (Danforth, 2011a).

Gamification expressed as a particular concept is relatively new, though the ideas behind it have been around for decades. Karl Kapp (2012) defines gamification as "using game-based mechanics, aesthetics and game thinking to engage people, motivate action, promote learning, and solve problems" (p. 10).

So gamification is neither pure play nor a formal game. Instead, it brings game elements into an environment, in this case using libraries, which normally wouldn't be a game. Typical gamification projects will use the language of games many people are familiar with into a nongame environment. Points; leaderboards; badges; levels, engaging imagery; and social interactions are all elements typically found in gamified systems. Unlike games, which may be used for many purposes, gamification focusses on playful engagement, and is increasingly used in marketing and health products to increase incentives to engage with products and systems.

\section{Implementation of Lemontree, a gamification platform}

The idea to implement a gamification project was initiated from an external design and creative company, Running in the Halls (RITH), who were interested in bringing more play (and particularly fun) into the library space.

RITH outlined a potential "gamification" idea for libraries, which they named Lemontree. This proposed a platform taking ideas from games to create an engaging environment within the library, providing a game "layer" over the top of normal library activities. This was recognised as a way to bring more playfulness into the library and allow us to investigate whether play and gamification may be an acceptable way to increase engagement with library resources.

When defining with the developers what was required from Lemontree, it was therefore important that the primary purpose was increasing engagement around the usage of library resources.

Thus, the implementation of Lemontree at the University of Huddersfield was built around "increasing the use of library information sources, including books and electronic resources". There were additional aims and objectives, including:

- Introduce a social game based learning system, Lemontree, into the University.

- Engage students with the academic process, by bringing an element of fun into the use of serious academic resources.

- Evaluate usage of library resources in Lemontree participants compared with non-participants.

- Evaluate student perceptions of social game based learning systems at the University of Huddersfield. 
The short term objectives of gamifying the library experience through Lemontree were about increasing the usage of library resources, as well as investigating how acceptable and engaging students found this approach. Longer term, the aim was to analyse whether any increased usage of library resources resulted in increased academic achievement. To measure the success of this longer term aim will take collection and analysis of usage data over several years.

Lemontree brings in competitive elements in order to drive engagement with the game layer and therefore with the usage of library resources. Alex Moseley (2012) lists some lessons from the games industry that can be used to increase engagement through educational games. These include some intangible aspects of games that Lemontree utilises such as points and leader boards; visual comparisons tracking performance against other players, where players get feedback in real time to see how they are performing; matching players with similar chances of "winning". These "light" competitive elements as used by Lemontree are aimed at providing "the most acceptable (and engaging) face of competition to most people" (p. 64). It was expected, therefore, that the light elements of competition that Lemontree brings into using library resources will be acceptable and engaging to the largest number of players, whereas a more serious game-like environment, with increased competition, may only engage a smaller proportion of members of the university.

There are many different motivations for players to participate in games. Zichermann and Cunningham (2011) delineated four motivations, for mastery; to de-stress; to have fun; and to socialize.

The platform attempts to address each of these motivations. There is a long and short term narrative built into the game. Long term, players grow their own graphic image of a lemon tree from a sapling to a fully grown tree laden with fruit as a visualisation of progress, or display of mastery, while a library card that changes from being freezing cold to being on fire illustrates short term activity. The light hearted nature of the interface and game layer tries to make using library resources less stressful as well as injecting an element of fun into library activities. Last, but not least, there are social elements built into the core of the game, including integration with Facebook, sharing comments on library resources with others, and gaining extra points for undergoing certain activities with Lemontree friends.

There are concerns over gamification projects, due to their virtual incentives to change behaviour and the associated extrinsic motivation they provide. Some say (Nicholson, 2012) that "intrinsic motivation", in other words, the internal motivation to carry out a task, can be destroyed by the "extrinsic motivation" that systems such as Lemontree can provide. The key concern is that once you remove the extra external motivation to carry out an activity, such as borrowing more books, behaviour may revert to previous patterns, or even fall below original levels of usage.

This is a well-known effect, and some of the key gamification gurus, including Zichermann and Cunningham (2011), warn us that if we start using gamification and rewards to increase extrinsic motivation for a task we may "have to keep her in that reward loop forever" (p. 27). This is similar to the way that diet clubs can help people lose weight, but participants may put weight back on if they stop attending meetings and lose their extrinsic motivation.

The Lemontree implementation at the University of Huddersfield addresses such concerns, in the following ways. First, the platform is available for the full duration of a student's academic studies, which is three years for the majority of our courses. If the system is discontinued, new registrations will cease, while the platform continues with existing participants, allowing them to continue to the end of their studies with access to the game. Because of the structure of our university, after three to four years we would expect to have only a very small number of people 
still playing, as most will have graduated. This would be the logical point where we could switch off access.

Second, the concern of this project is the direct impact that using the library and information sources has on academic achievement. In the long term, if there is proved to be a causal link, increased access to books and online materials will have already impacted on student achievement. The removal of the extra incentive to use more information resources will not remove its previous impact, meaning there would be minimal adverse effect on our student population.

Finally, Lemontree aims to gently 'nudge' behaviour, rather than dramatically changing it. Rewards are small and virtual, providing small virtual rewards as feedback for positive behaviour. If people are seeking primarily large numbers of points for their own sake, then there is a chance that people will "game" the system and borrow items, or access increased numbers of electronic resources without actually using those materials for their studies. We have watched the system for evidence of such "cheating" and so far have only found evidence of one player acting in such a way. This player borrowed large numbers of books then almost immediately returned them, which generated an instant and significant boost to his standing in the leader boards. This is perhaps the most obvious way of cheating the system, and we expected to see it happen more often. It has been pleasing to see that only one player so far has done this, with the resulting quick boost in points easy to spot. We are therefore confident that few users are borrowing items purely to gain extra points.

It has been suggested that Lemontree should offer real world rewards for participating such as printer credit, book vouchers, or iPods. These could be awarded when users hit key achievements or to those who were top of the leaderboard at certain times. The evidence suggests, however, that bringing in such sources of compensation, or extrinsic motivation, to take part would decrease overall motivation to participate (Deci, Koestner, \& Ryan, 1999). Instead, the developers, focussed on helping to support intrinsic motivation to use the library, helping students in order to reduce library anxiety, rather than layering coarse extrinsic motivation factors over the top of our users' existing motivations.

Lemontree aims to nudge positive behaviour, supporting and increasing intrinsic motivations, as McGonigal (2012) says, “Games don't fuel our appetite for extrinsic reward: they don't pay us, they don't advance our careers, and they don't help us accumulate luxury goods. Instead, games enrich us with intrinsic rewards."(p. 50)

\section{Development of Lemontree, its features, and implementation}

The development work for Lemontree (live at http://library.hud.ac.uk/lemontree) has been carried out by external partners of the university, RITH (Running in The Halls). This is a fully featured online gamification of library activities, including awarding points and badges for borrowing and returning items, leaving reviews, entering the library, and using online resources.

Once students have registered online through the Lemontree web page, and given permission to share their own usage data with the system, they will automatically start to gain points and progress through Lemontree's levels. At any time users can choose to switch their account to private and hide their data from other users, while still gaining points.

A programme on the library's servers automatically polls various library systems to identify pre-set activities and passes this information to Lemontree itself. We detect if a player enters the library (as they are required to scan their library card to enter the building); if they issue or return any physical items; and if they authenticate on our systems to access electronic resources. 
When Lemontree has receives this information, it extracts the basic data and generates points based on pre-set criteria. These are then awarded to the players account and displayed on the Lemontree interface in real time, unless the user has chosen to switch on additional privacy settings.

These privacy settings allow a user to anonymise their data when displayed, so the user is not identifiable, which can be for a temporary period if wished. One of the basic principles underneath the implementation of Lemontree at this institution is that users should have access to and control over their own data. Lemontree shares this data publicly, but only if members of the university choose to opt-in by signing up to the system, and allows them to hide their activity data at any time.

For example, we are able to offer different points and badges for entering the library at different times of day, such as an "early bird" badge for entering five times before $10 \mathrm{am}$, a time when it is easy to find study spaces and the library is less crowded and intimidating to some potential users. We offer a range of badges for borrowing a set amount of items from different sections of Dewey numbers to encourage the use of a wide range of books, as this information can be pulled into Lemontree in real time. The developers aimed to encourage exploration of the library and our resources through the safe, fun environment of Lemontree, rather than sticking to the minimal, set patterns of usage we were concerned were being exhibited by some of our more infrequent library users.

It is delivered through an attractive, well designed interface, designed to look as fun and light hearted as possible, with no university or library branding visible. This is an important part of our aim to reduce library anxiety and engage low users of our resources. Using Lemontree should feel almost like something slightly "naughty" or unofficial, a game tagged onto the library by others, rather than something our users directly associate as an "official" project that is designed to be good for them.

The project was launched early in November 2011, slightly behind schedule. This meant a key part of the promotional plan was missed, which was to publicize the project to new students as they arrived. We had planned to carry this out in library inductions during September and October, where we expected to be able to register several hundred students as users, growing organically from that base over the rest of the academic year.

The project was successful in attracting users through a range of low key, "fun" and graphic promotional techniques. Lemontree is promoted through images on plasma screens across the university, using bright positive images to draw new users into joining the game. Promotional activities also used social networks, including Twitter, with even the Vice Chancellor tweeting messages encouraging people to participate. We have used a banner on certain key library websites to encourage new users to the game and recent activity is now embedded in our main library search page. Finally, we have introduced "reality points", the usage of physical objects that link to the online game. These include two different sizes of cards, some of which offer bonus points within the game. We have used a series of small badges given out at "freshers' fair" at the start of our academic year, whose images link to the virtual badges in Lemontree online.

\section{Early evaluation}

Other than the initial delay to launch, the project has been successful in attracting and engaging users so far, with over 1,000 users registered by the end of the first year of operation.

It is difficult to measure the direct impact, particularly whether we really have increased the usage of library resources in Lemontree participants compared with non-participants. This 
will only become apparent as we collect library usage data over the longer term, following students through their time at university.

Most of the other objectives can be seen to be met by the quantity of usage the game has received and the positive qualitative feedback we have received. This has been especially true for the perceptions of social gaming systems and two pieces of unprompted feedback are shown below - one from Twitter, one from Facebook.

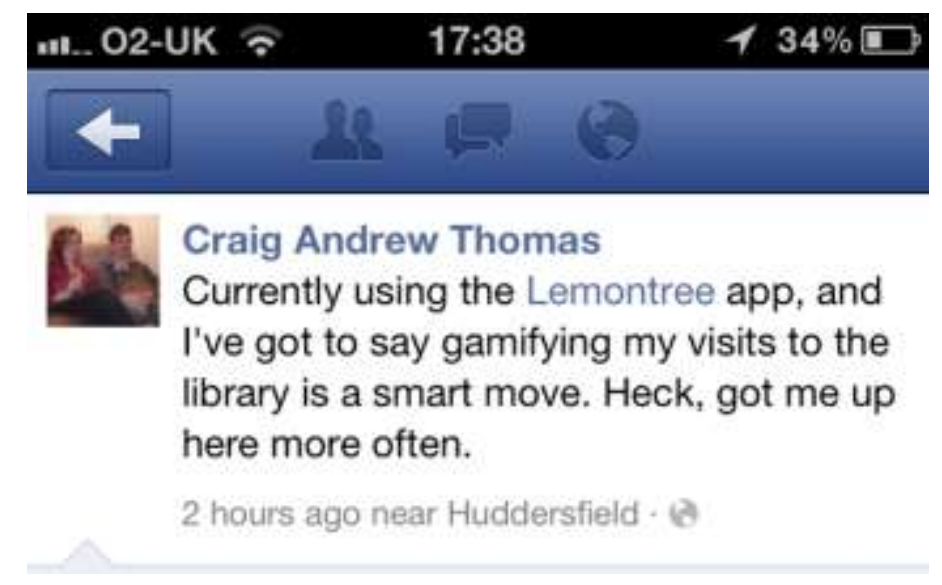

Figure - Facebook feedback.

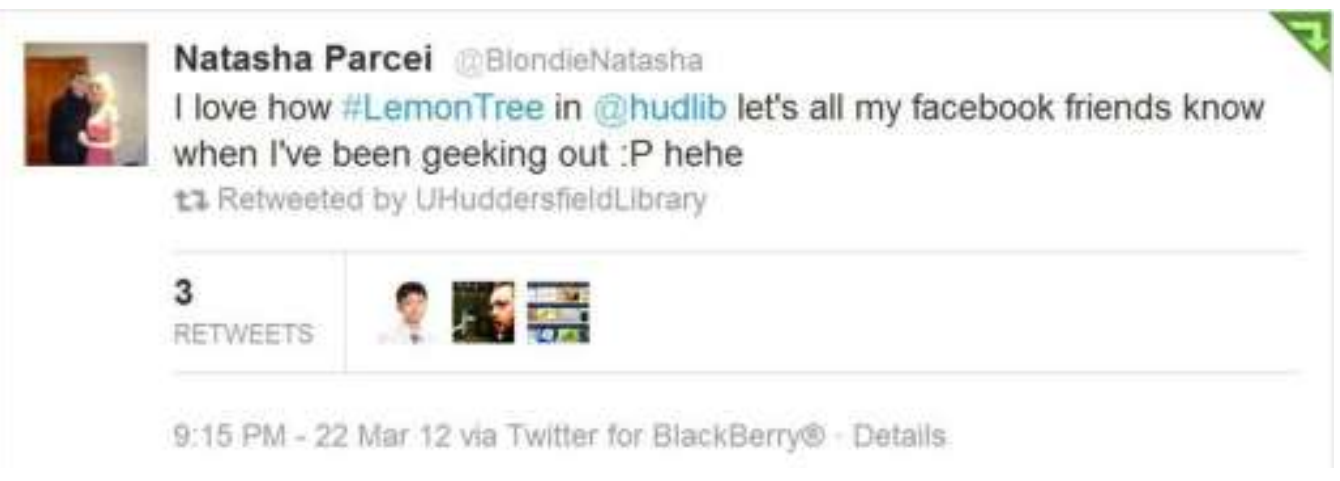

Figure - Twitter feedback.

An early survey of users, promoted directly to registered users in early 2012, has given us overwhelmingly positive feedback. Overall impressions of the game included:

- Brilliant idea that has the potential to be a lot of fun.

- I enjoy the introduction of the game element

- Quirky and unique type of game

- Very good, I like it. Encourages me to visit the library more often.

- Very impressed with it. I've definitely visited the library more frequently since its implementation.

The survey also showed, however, that they expected the game to continue to develop and that it needed more work: 
- Good idea, definitely needs a few tweaks and extra features to improve it.

- I like it, it adds an element of fun to using the library and its resources. I'm not $100 \%$ sure it encourages or ensures effective use of those resources but that probably isn't the point to it.

- It's good but needs more to it. Maybe like a chat function similar to FB and for achievements to show what they are and how to achieve them.

- I think Lemontree should be easier to access. By this I mean I currently have to log in to my library account and then go onto Lemontree. It would be better if the two were integrated more fully. Or if Lemontree was integrated into the current Unilearn system [our Virtual Learning Environment] as an extra tab at the top.

This early feedback and evaluation was followed up by a later survey in January 2013. The survey targeted Lemontree users who had been registered on the system for at least one academic term, to ensure they had experience of using the system. Out of 762 users registered in October 2012 (early in the first term of our academic year), who had a valid email contact address, we received 156 responses. This corresponds to a $20.5 \%$ response rate, an acceptable rate for an online survey.

When asked if they felt the interactions within Lemontree encouraged them to change their library usage behaviour, the majority of students $(60 \%)$ responded that it did so in one or more ways. This was a pleasant surprise, as we felt that by using the gentle encouragement of this style of gamification, we would have subtle effects on usage, which the users themselves may not have directly recognised.

One survey question asked "Do you fell the interactions within Lemontree encourages you to change your behaviour, such as borrowing more books, or accessing more electronic resources? Please tick all that apply!" and the results follow below:

\begin{tabular}{l|c} 
Borrow more books & $\mathbf{5 6}(\mathbf{3 6 \% )}$ \\
\hline Borrow a wider range of books & $36(23 \%)$ \\
\hline Come into the library more often & $69(44 \%)$ \\
\hline $\begin{array}{l}\text { Come into the library at different } \\
\text { times }\end{array}$ & $39(25 \%)$ \\
\hline Use more electronic resources & $57(37 \%)$ \\
\hline Has not changed my behaviour & $63(40 \%)$ \\
\hline Other & $10(6 \%)$
\end{tabular}

Few Lemontree users had previous experience of gamification, with only $16.7 \%$ using (or having previously used) another platform which they recognised as "gamified". Despite this limited experience, $85 \%$ of respondents said they felt gamification was appropriate within education. Only $5 \%$ said they thought it was inappropriate, with a further $10 \%$ ambivalent or unsure. Free text responses were allowed under the question of whether gamification was appropriate, with the following themes occurring regularly: 


\begin{tabular}{|lc|}
\hline Theme & Number of Occurrences \\
\hline Encouraging / incentivising / engaging & 49 \\
\hline Fun / entertaining & 40 \\
\hline Facilitate learning & 14 \\
\hline Reward & 10 \\
\hline Competition & 9 \\
\hline Giving social affordances & 9 \\
\hline Distracting or inappropriate & 9 \\
\hline Interactivity & 5 \\
\hline Providing variation in experience & 4 \\
\hline
\end{tabular}

This largely reflection our own assumptions as we introduced Lemontree, which we hoped would take elements of play and games to make the library a more fun, less "scary" place to interact with, using virtual rewards and competition to facilitate improved learning. It reinforces the idea that it would encourage members of the university to engage more with library resources.

\section{Conclusion and future developments with Lemontree}

It has been shown through the Library Impact Data project (Stone \& Collins, 2013; Stone \& Ramsden, 2013) that there is a correlation between positive student outcomes and usage of university library resources, with suggestions that there may be a causal link, though this has yet to be completely proved. Play, and gamification in particular, is well placed to build engagement (Danforth, 2011b; Sukovic, Litting \& England, 2011) and the implementation of Lemontree builds on previous evidence that using such techniques to encourage positive behaviour can be well received (Danforth, 2011b; Kurt, Kurt \& Medaille, 2010).

The feedback on Lemontree suggests that users can accept a gamification system in a university setting, and readily engage with it. That said, such an approach could only ever be part of a suite of tools to increase student engagement. The proportion of a student population using such a system is limited by one of the key ideas of what makes a game - it must be optional (Huizinga, 1949). Once an activity becomes compulsory, it ceases to be a game and instead becomes "work". So, a university could not sign up students as "players" and expect the same response from all students. It must always be one element among a set to be used in increasing student engagement.

Those students that do choose to play Lemontree self-reported an increase in engagement, as measure by reported usage of library resources. This suggests that gamification systems such as Lemontree are worth persisting with for several years in order to collect quantitative data that may be analysed for statistically relevant correlations between use of a gamification project and wider engagement with resources.

For the Lemontree platform itself, it may be desirable to increase further the social elements in the game, which were underdeveloped in comparison to many gamification platforms. An important part of increasing engagement and reducing library anxiety is making 
users feel they are not alone (Carlile, 2007), which may be done by encouraging sharing with others. Bringing this increased social sharing of experiences (through reviews, comments and shared book lists) should help reduce the anxiety of some users in making full use of library resources.

In addition to improvements in social sharing, it would also be desirable to increase visibility further of 'easy to access' library resources, perhaps by integrating reading list software into the platform. As the primary place that students start discovering library resources, reading lists should be a productive integration to Lemontree. Giving rewards for breadth of items accessed from a reading list should help exploration of material beyond core texts and into those considered background reading. Tying it into the newer social elements, and allowing people to share their own highlights from a list, should encourage reflection and deeper learning on the part of the list creator within Lemontree. It may also result in increased legitimisation of reading list material, with items recommended by students' peers as well as their lecturers.

The techniques tried here have other, more general applications, using games, fun and play for serious outcomes. Lemontree and the results of our survey show that these techniques are acceptable and welcomed by members of the university and open the way for further development of the use of games and fun within library services and higher education. 


\section{References}

Astin, A. W. (1968). Undergraduate Achievement and Institutional "Excellence". Science, 161(3842), 661-668.

Axelson, R. D., \& Flick, A. (2011). Defining Student Engagement. Change: The Magazine of Higher Learning, 43(1), 38-43.

Brown, S. L., \& Vaughan, C. C. (2010). Play: how it shapes the brain, opens the imagination, and invigorates the soul. New York: Avery.

Carini, R. M., Kuh, G. D., \& Klein, S. P. (2006). Student Engagement and Student Learning: Testing the Linkages. Research in Higher Education, 47(1), 1-32.

Carlile, H. (2007). The implications of Library Anxiety for academic reference services: A review of the literature. Australian Academic \& Research Libraries, 38(2), 129-147.

Danforth, L. (2011a). Gamification and Libraries. Library Journal, 136(3), 84-84.

Danforth, L. (2011b). Why Game Learning Works. Library Journal, 136(7), 67-67.

Deci, E. L., Koestner, R., \& Ryan, R. M. (1999). A meta-analytic review of experiments examining the effects of extrinsic rewards on intrinsic motivation. Psychological bulletin, 125(6), 627-668.

Fitz-Walter, Z., Tjondronegoro, D., Koh, D., \& Zrobok, M. (2012, 2012). Mystery at the library: encouraging library exploration using a pervasive mobile game. Paper presented the OzCHI '12 Proceedings of the 24th Australian Computer-Human Interaction Conference, Melbourne, Australia.

Foster, R., \& Gadd, S. (2013). Let's play Supermarket 'Evidential' Sweep: developing students' awareness of the need to select evidence. Teaching History(152), 24.

Gallegos, B., Allgood, T., \& Grondin, K. (2007). Quarantined: The Fletcher Library Game Project. Paper presented at the LOEX.

Huizinga, J. (1949). Homo ludens: a study of the play-element in culture. London: Routledge and Kegan Paul.

Kapp, K. M. (2012). The gamification of learning and instruction: game-based methods and strategies for training and education. San Francisco: Pfeiffer.

Kuh, G. D., Kinzie, J., Buckley, J., Bridges, B., \& Hayek, J. (2006). What Matters to Student Success: A Review of the Literature. . Washington: National Postsecondary Education Cooperative.

Kurt, L., Kurt, W., \& Medaille, A. (2010). The power of play: Fostering creativity and innovation in libraries. Journal of Library Innovation, 1(1), 8-23.

Lane, G. (1966). Assessing the Undergraduates' Use of the University Library. College and Research Libraries, 27(4), 277.

Markey, K., Swanson, F., Jenkins, A., Jennings, B. J., St. Jean, B., Rosenberg, V., . . Frost, R. L. (2008). The Effectiveness of a Web-based Board Game for Teaching Undergraduate Students Information Literacy Concepts and Skills. D-Lib Magazine, 14(9/10). doi: 10.1045/september2008-markey

McDevitt, T. (Ed.). (2011). Let the games begin! Engaging students with field-tested interactive information literacy instruction. New York: Neal-Schuman. 
McGonigal, J. (2011). Reality is broken: why games make us better and how they can change the world. London: Jonathan Cape.

Mellon, C. A. (1986). Library Anxiety: A Grounded Theory and Its Development. College and Research Libraries, 47(2), 160.

Moseley, A. (2012). Competition: Playing to win? In N. Whitton \& A. Moseley (Eds.), Using games to enhance learning and teaching: A beginners guide. London: Routledge.

Nagata, H., \& Toda, A. (2007). Students' Patterns of Library Use and Their Leaning Outcomes. Joho Media Kenkyu, 6(1), 19.

Nichols, R. C. (1964). Effects of various college characteristics on student aptitude test scores. Journal of educational psychology, 55(1), 45-54.

Nicholson, S. (2012). A User-Centered Theoretical Framework for Meaningful Gamification. Paper presented at the Games+Learning+Society 8.0 Conference, Madison, WI. June 2012. http://scottnicholson.com/pubs/meaningfulframework.pdf

Rock, D. A., Centra, J. A., \& Linn, R. L. (1970). Relationships between College Characteristics and Student Achievement. American Educational Research Journal, 7(1), 109-121.

Rosenstein, J. (2013). Ghost hunters in the library. College and Research Libraries News, 74(7), 350-353.

Smale, M. (2011). Learning Through Quests and Contests: Games in Information Literacy Instruction. Journal of Library Innovation, 2(2), 20.

Smith, A.-L., \& Baker, L. (2011). Getting a clue: creating student detectives and dragon slayers in your library. Reference Services Review, 39(4), 628-642.

Stone, G., \& Collins, E. (2013). Library usage and demographic characteristics of undergraduate students in a UK university. Performance Measurement and Metrics, 14(1), 25-35.

Stone, G., \& Ramsden, B. (2013). Library Impact Data Project: looking for the link between library usage and student attainment. College and Research Libraries, 74(6), 546-559.

Sukovic, S., Litting, D., \& England, A. (2011). Playing with the Future: Library Engagement and Change. Australian Academic \& Research Libraries, 42(2), 70-87.

Taylor, L. N., Davis, V., Gonzalez, S. R., Dinsmore, C., \& Frey, C. (2008). Bioactive : a game for library instruction at the University of Florida. In A. Harris \& S. Rice (Eds.), Gaming in Academic Libraries: Collections, Marketing, and Information Literacy. Chicago: Association of College \& Research Libraries.

Zichermann, G., \& Cunningham, C. (2011). Gamification by design: implementing game mechanics in web and mobile apps. Sebastopol: O'Reilly 